DOI 10.37882/2223-2982.2021.03-2.24

\title{
3ООСЕМИЗМЫ И ЗООНИМЫ В СОСТАВЕ ФРАЗЕОЛОГИЧЕСКИХ ЕДИНИЦ
}

\section{ZOOSEMISMS AND ZOONYMS IN PHRASEOLOGICAL UNITS}

Li Yimo

Summary: The paper discussed the difference between phraseological zoonymic meaning and zoosemic meaning. The terms zoonym, zoomorphism and zoosemism are often confused in scientific terminology. On the material of "Russian Semantic Dictionary», "Dictionary of offensive words» L.V. Dulichenko and «Ideographic Dictionary of Russian phraseological units with the names of animals» T.V. Kozlov, described types of relations between phraseological zoonymic meanings and zoosemic meanings. Focused on comparing the characteristics of the values of those and other units. The study revealed three types of discrepancies between phraseological zoonymic meaning and zoosemic meaning. The necessity of differentiation has been proved.

Keywords: zoosemism, zoonym in phraseological units, metaphor, compare, Russian explanatory dictionaries.

\section{1. Фразеологическое зоонимическое значение и зоосемическое значение в научной терминологии}

И сследование семантического поля животных находится в центре внимание многих исследователей. Употребление связанных с названиями животных терминов зооним и зоосемизм, зооморфизм в научной литературе варьируется. При этом оказываются не выявленными существенные различия между соответствующими понятиями.

Вопросы, связанные с проблемой поиска терминологического обозначения, затрагиваются в работах разных исследователей: А.А. Курбанов [6], Р.В. Патюкова [12], А.Г. Соколова [15], М.А. Гаврилюк [1], Г.Н. Скляревская [14], Ц.Ц. Огдонова [10], А.А Киприянова [4], В.П. Москвин [9] и др.

Так, например, А.С. Маслова представляет семантическую структуру названия животного следующим образом: первая номинация (зооним), вторая номинация (зоометафора), промежуточная позиция (зооморфизм). «В отличие от зоометафоры, зооморфизм воспринимается как способ обозначения индивидуализированного автором субъективного символа, причём результат метафорического переноса не является его единственным референтом» $[8$, с. 52].

\author{
Ли Имо \\ Aсnирант, Университет МГУ-ППИ в Шэньчжэне, Китай; \\ Московский государственный университет \\ имени М.В. Ломоносова, Россия \\ liyimo@mail.ru
}

Аннотация: В работе рассматривается различие фразеологического зо0нимического значения и зоосемического значения. Термины зооним, зооморфизм и зоосемизм часто смешиваются в научной терминологии. На материале «Русского семантического словаря», «Словаря обидных слова» Л.В. Дуличенко и «Идеографического словаря русских фразеологизмов с названиями животных» Т.В. Козловой описаны типы отношений между фразеологическими зоонимическими значениями и зоосемическими значениями. Акцентируется внимание на сопоставлении характеризующих значений тех и других единиц. Исследование выявило три типа несовпадений фразеологического зоонимического значения и зоосемического значения. Доказывается необходимость разграничения этих единиц.

Ключевые слова: зоосемизм, зооним в составе фразеологизма, метафора, сравнение, русские толковые словари.

М.В. Шульга устанавливает существенные различия между зоосемизмами и зоонимами в грамматическом аспекте. Она показывает, что в процессе метафоризации у зоосемизмов происходит переосмысление отношений между грамматическим родом и биологическим полом, зоосемизмы адаптируются в кругу личных существительных [20, с. 49-62], также [19];[7].

В данной работе вторичные названия лиц (метафоры), мотивированные названиями животных (зоонимами), мы обозначаем термином зоосемизмы [4; 19; 20]. В другой терминологии: зооморфные метафоры [16, 14], зоометафоры [8, 3; 17].

Таким образом, в теоретическом аспекте мы разграничиваем зоонимы и зоосемизмы. Дальше мы акцентируем внимание на различиях зоонимического значения во фразеологизме и зоосемического значения.

\section{2. Зоонимы в составе фразеологических ециниш и зоосемизмы}

По образному определению Е.В. Падучевой, «Фразеология - бедная родственница метафоры и вынуждена довольствоваться лишь мелкими подачками» [11, с. 187-202].

Д.О. Добровольский рассматривает системность иди- 
оматических единиц и отмечает её своеобразие на фоне лексики. Несмотря на то, что идиоматике, как и лексике, свойственна регулярная многозначность, не для всех конкретных идиом можно предсказать направление семантического развития, как в лексике (автор называет это «грамматикой лексики»). Поэтому идиомы были и остаются «штучным товаром» [2, с. 77-88].

Для целей нашего исследования принципиально важным является разграничение собственно зоосемических (метафорических) и зоонимических характеризующих значений. Зоонимы с характеризующими значениями широко представлены в относительно устойчивых сочетаниях лексем разного типа: во фразеологизмах, в сравнениях, поговорках, пословицах. Далее мы эти устойчивые сочетания рассматриваем не дифференцированно.

Мы следуем за сформировавшейся лексикографической традицией и рассматриваем их как зоонимы в составе фразеологии. Такое широкое понимание фразеологии представлено, например, в словаре Т.В. Козловой: «Под фразеологической единицей понимается воспроизводимое, относительно устойчивое сочетание лексем, как правило, обладающее целостным значением и экспрессивностью» [5, с. 7]. В перечень фразеологизмов С зоонимами (в индекс словаря) включены не только собственно фразеологизмы, но также сравнительные обороты и пословицы. Например: здоровый как бык; сорока нахвосте принесла.

В «Идеографическом словаре русских фразеологизмов с названиями животных» Т.В. Козловой насчитывается 2000 фразеологизмов с 283 названиями животных, которые употребляются в современном литературном языке и в ряде диалектов [5, с. 2].

Известно, что фразеологически связанное значение слова отличается от его свободного значения, так же не совпадает значение зоонима и зоосемизма. Исследование показало, что степень этого несовпадения бывает разной.

Русские зоосемизмы в наиболее полном объёме и составе представлены в «Русском семантическом словаре» [13] и «Словаре обидных слов» Л.В. Дуличенко [18], отражающих основные принципы их лексикографического описания. Методом сплошной выборки материала в двух русских изданиях нами выявлено 162 зоосемизма.

Между двумя русскими словарями имеются расхождения в составе лексического подкласса зоосемизмов что отчасти связано с лексикографическими принципами базовых словарей, отчасти отражает субъективность лексикографических решений при описании переносных значений. Этот факт выявляет сферу недостаточной изученности рассматриваемого феномена.

Наша задачи состоит в сопоставлении характеризующих значений зоосемизмов и зоонимов в составе фразеологизме. Среди 162 выявленных нами зоосемизмов 45 зоосемизмов имеют соотносительные зоонимы в словаре Т.В. Козловой.

\section{3. Характеризуюшие признаки зоонимов в составе фразеологических еАиниц и зоосемизмов}

Отношения между метафорическим и фразеологическим значениями зоонимов различны. При исследовании материала мы встречаемся со следующими тремя типами ситуаций.

1. У зоосемизма при метафоризации может быть актуализирована часть характеризующих признаков, ассоциирующихся с соответствующим зоонимом в составе фразеологизмов.

2. Помимо части признаков, характерных для зоонима во фразеологии, у зоосемизма может быть актуализирован дополнительный характеризующий признак или дополнительные признаки.

3. Зооним во фразеологии и зоосемизм могут различаться характеризующими признаками, эти признаки могут даже противоречить друг другу.

К первому типу относятся 14 зоосемических единиц: у зоосемизмов гусыня, зверь, змея, кобель, корова, лиса / лисица, осёл, петух, попугай, сорока, червь, ягнёнок, индюк, кот при метафоризации может быть актуализирована часть характеризующих признаков, ассоциирующихся с соответствующим зоонимом в составе фразеологизмов.

Образы зоонима гусыня во фразеологизмах включают следующие «наиболее устойчивые характеристики и смысловые аспекты»: 'ходит переваливаясь, горделивый, степенный, важный, замёрзнуть, самодовольный, хитрый, изворотливый, лицемерный, нахальный' [5, с. 8]. Эти признаки отчасти отражены и у зоосемизмов. Зоосемизм гусыня - по характеризующим признакам 'полный, ходит не спеша, покачиваясь, вразвалку' [18].

Зооним зверь во фразеологизмах воспринимается через представления:'злой, свирепый, сердитый, разъярённый, яростный, жестокий, тревожный, беспокойный, необузданный, с плотскими наклонностями' [5, с. 8]. 3оосемизм зверь характеризует человека по аналогичным признакам, однако спектр этих признаков намного уже: 'жестокий, свирепый, беспощадный' [13, с. 116]. Так же в словаре Л. В. Дуличенко: 'жестокий, свирепый' [18, с. 62].

Зооним змея во фразеологизмах воспринимается через представления: 'некрасивый, неприятный, мудрый, 
с плохим характером, злой, жестокий, хитрый, льстивый, подхалим, лицемерный, коварный, неблагодарный' [5, с. 9]. У зоосемизма змея актуализирована часть этих признаков: 'злой и коварный, злобно-язвительный' [13, с. 117]. Так же в словаре Л. В. Дуличенко: 'злой и коварный, хитрый' [18, с. 65].

Образ кобель ассоциируется во фразеологии с представлениями: 'похотливый, распутный, лжец' [5, с. 9]. 3оосемизм кобель характеризует человека по одному из этих признаков:'похотливый' [13, с. 107; 18, с. 77].

Образ корова ассоциируется во фразеологизмах с представлениями: 'большеглазый, неуклюжий, верзила, толстый, плодовитый, одетый без вкуса, легкомысленный, гулящий, похотливый, нерасторопный, бездельник, безответный, тихий, безобидный, плачущий навзрыд, криком, скандалист' [5, с. 9]. Зоосемизм корова характеризует человека по некоторым из этих признаков: 'толстый, неповоротливый' [13, с. 332].

Образ лиса / лисица ассоциируется во фразеологизмах с представлениями: 'хитрый, льстивый, изворотливый, лицемерный, коварный, опасный, обманщик, подхалим' [5, с. 9]. Зоосемизм лиса / лисица характеризует человека по некоторым из этих признаков: 'хитрый, льстивый' $[13$, с. $111 ; 18$, с. 93].

Зооним осёл во фразеологии ассоциируется с представлениями: 'тощий, костлявый, глупый, покорный, упрямый, несговорчивый, ленивый, работящий' [5, с. 10]. У зоосемизма осёл актуализированы некоторые из этих признаков: 'упрямый, глупый' [13, с. 90; 18, с. 121].

Зооним петух во фразеологии ассоциируется с признаками: 'задиристый, самодовольный, раннее утро' [5, с. 10]. У зоосемизма петух актуализирована часть этих признаков: 'задиристый, запальчивый, забияка' [13, с. $116 ; 18$, с. 130].

Зооним попугай во фразеологии ассоциируется с признаками: 'яркий, пёстрый, повторять, передразнивать' [5, с. 10]. У зоосемизма попугай актуализирована часть этих признаков:'не имея собственного мнения, повторяет чужие слова' [13, с. 103; 18, с. 139].

Образ сорока ассоциируется во фразеологизмах с представлениями: 'с конопатым, веснушчатым лицом, болтливый, сплетник, неблагодарный, вор' [5, с. 10]. У зоосемизма сорока актуализирована часть этих признаков: 'болтливый' [13, с. 121; 18, с. 181].

Образ червь ассоциируется во фразеологизмах с представлениями: 'невзрачный, маленького роста, больной, извиваться телом, унижается, угодничать, тоска, смерть' [5, с. 11]. У зоосемизма червь актуализиро- вана часть этих признаков: 'ничтожный, приниженный' $[18$, c. 223].

Зооним ягнёнок во фразеологии ассоциируется с признаками: 'безвольный, кроткий, послушный, добрый' [5, с. 11]. У зоосемизма ягнёнок актуализирована часть этих признаков: 'кроткий, незлобивый' [13, с. 97].

Зооним индюк во фразеологии ассоциируется с признаками: 'спесивый, высокомерный, самодовольный, жирный, толстый, смешной, хмурый, разозлившийся' [5, с. 11]. У зоосемизма индюк актуализирована часть этих признаков: 'заносчивый, надменный' [13, с. 102].

Образ кот ассоциируется во фразеологизмах с представлениями:'блудливый, игривый, нерешительный, осторожный' [5, с. 9]. У зоосемизма кот актуализирована часть этих признаков:'похотливый сластолюбец' [13, с. 107].

Ко второму типу относятся 10 зоосемических единиц: у зоосемизмов бык, боров, голубь, кляча, коза, ласточка, лошадb, пава, птица, сокол при метафоризации может быть актуализирован дополнительный характеризующий признак или дополнительные признаки.

Зооним бык во фразеологизмах включает следующие признаки: 'крепкий, здоровый, сильный, с короткой, сильной шеей, выносливый, обжора, недовольный, упрямый' [5, с. 8]. Зоосемизм бык характеризует человека по некоторым из этих признаков, но у него есть также другие признаки: 'упрямый, сильный, здоровый - грубый, жестокий' [18, с. 27].

Образ боров связан во фразеологии с представлениями: 'толстый, недовольный' [5, с. 8]. Зоосемизм боров характеризует человека через такие признаки как: 'толстый, неповоротливый' [13, с. 423; 18, с. 23].

С образом голубь во фразеологии связаны представления:'маленький, чистый, невинный, кроткий, безобидный, миролюбивый, ласковый, влюбленный, наивный, простодушный' [5, с. 8]. Зоосемизм голубь характеризует человека по части этих признаков, но также по дополнительному признаку: 'ласковое и снисходительное обращение к собеседнику - вообще упоминание о том, кто близок или кому сочувствуют' [13, с. 348].

С образом кляча во фразеологии связаны представления: 'старый, слабый, медленно движущийся' [5, с. 9]. Зоосемизм кляча характеризует человека по части этих признаков, но также по дополнительному признаку: 'немощный - исхудалый' [13, с. 332]. В словаре Л. В. Дуличенко метафорическое значение кляча более конкретно:'худой, еле стоящий на ногах человеке' [18, с. 77].

Зооним коза отражает во фразеологии представле- 
ния: 'подвижный, бегущий скачками, быстрый, лёгкость движений, с бестолковыми движениями, усталый, измождённый, нелюдим, зазнайка, незначительный, бесполезный, упрямый, бездельник, подражать, ломаться' [5, с. 9]. Зоосемизм коза характеризует человека по части этих признаков, но также по дополнительному признаку: 'непоседливый - непослушный и назойливый, молодой' $[18$, c. 78].

Зооним ласточка во фразеологизмах ассоциируется с представлениями: 'ласковый, чистый, целомудренный' [5, с. 9]. Зоосемизм ласточка характеризует человека по части этих признаков, но также по дополнительному признаку:'ласковый - вообще упоминание о том, кто дорог, близок, кому сочувствуют' [13, с. 349].

Зооним лошадь во фразеологизмах ассоциируется с представлениями: 'что-либо больших размеров, много ест, храпеть, нестройный, нескладный, здоровый, сильный, выносливый, хитрый, скрытый, пугливый, работяга' $[5$, c. 9].

Зоосемизм лошадь включает один из этих характеризующих признаков, но также и другой признак, и в разных словарях отражается по-разному: В Семантическом словаре: 'нескладный - рослый, крупный' [13, с. 332]. В словаре Л.В. Дуличенко отражает сему 'работяга' и дополняет сему намерение использовать человека:'на непомерно тяжёлой работе - человек, которого используют в корыстных целях' [18, с. 97].

Зооним пава отражает во фразеологии представления: 'важный, статный, горделивый' [5, с.10]. Зоосемизм пава включает один из этих характеризующих признаков, но также и другой признак: 'горделивая осанка плавная походка и манерные жесты' [18, с. 124].

Зооним птица отражает во фразеологии представления: 'мало ест, быстрый, проворный, свободный, беззаботный, непоседа, одинокий, пугливый, глупый, неопытный, наивный, доверчивый, бывалый, важная особа, незначительный человек' [5, с.10].

Зоосемизм птица включает некоторые из этих характеризующих признаков, но также и другой признак: 'важный, неизвестный - непонятный' [13, с. 68]. В словаре Л.В. Дуличенко отражается более обобщенный признак, метафорическое значение шире:'претендующий на особое положение среди других' [18, с. 153].

Зооним сокол отражает во фразеологии представления: 'зоркий, видный, красивый' [5, с.10]. Зоосемизм сокол включает только один из этих характеризующих признаков, но также и другой признак: 'красивый - сильный; ласковое обращение, доброжелательный' [13, с. 350].
К третьему типу относятся 12 зоосемических единиц: зоосемизмы и зоонимы волк, ворона, гусь, жеребец, кобыла / кобылица, лев, овца, пёс, рыба, сова, трутень, сыч могут различаться характеризующими признаками.

Образ волк связан во фразеологии с представлениями: 'истощенный, голодный, прожорливый, здоровый, строгий, сердитый, кровожадный, жестокий, коварный, скрытный, бывалый, работящий' [5, с. 8]. У зоосемизма волк актуализированы иные признаки:'недружелюбный, враждебно настроенный' [18, с. 31].

Образ ворона связан во фразеологии с представлениями: 'чёрный, блестящий, грязный, предвещающий беду, смерть, жадный, алчный, глупый, трусливый' [5, с. 8]. У зоосемизма ворона актуализированы иные признаки: 'тот, кто упустил свою выгоду, удачу, по рассеянности или недомыслию не сумел воспользоваться чем-н. [13, с. 104]. В словаре Л.В. Дуличенко: 'рассеянный, невнимательный' [18, с. 32].

Образ гусь во фразеологии ассоциируется с признаками: 'ходит переваливаясь, горделивый, степенный, важный, замёрзнуть, самодовольный, хитрый, изворотливый, лицемерный, нахальный' [5, с. 8]. У зоосемизма гусь актуализированы признаки: 'ловкач и мошенник' [13, с. 110]. В словаре Л.В. Дуличенко: 'ненадёжный или плутоватый' [18, с. 43].

Образ жеребец во фразеологии ассоциируется с признаками:'громко смеяться, неуклюже танцевать' [5, с. 8].У зоосемизма жеребец актуализированы признаки:'здоровый, сильный, крепкого сложения, избегающий тяжёлой работы' $[13$, с. 332].

Образ кобыла / кобылича связан во фразеологии с представлениями: 'молодой, подвижный' [5, с. 9]. У зоосемизма кобыла / кобылица актуализированы иные признаки:'рослый, здоровый' [13, с. 332].

Зооним лев в фразеологизме ассоциируется с признаками:'смелый, злой, свирепый' [5, с. 9]. Зоосемизм лев отражает только положительный признак: 'человек высшего света'[13, с. 137].

Зооним овца ассоциируется во фразеологии с представлениями: 'беспомощный, безропотный, послушный, беспамятный, бестолковый, бесполезный, клеветник' [5, с. 10]. У зоосемизма овца актуализированы иные признаки: 'робкий и безответный' [13, с. 114].

Зооним пёс во фразеологии ассоциируется с представлениями: 'верный, заискивающий, подобострастный, грустный, подавленный' [5, с. 10]. Зоосемизм пёс включает другие характеризующие признаки:'быть готовым на любые низкие поступки, дела' [13, с. 119]. В сло- 
варе Л. В. Дуличенко: 'вызывать презрение, негодование своими поступками' [18, с. 130].

Зооним рыба во фразеологизме отражается с признаками: 'хорошо плавающий, задыхающийся, молчаливый' [5, с. 10]. Зоосемизм рыба выражается другие признаки: 'вялый, холодный' [13, с. 105]; 'медлительный бесстрастный' $[18$, с. 165].

Зооним сова во фразеологии ассоциируется с представлениями: 'с круглыми, выпученными, невыразительными глазами' [5, с. 10]. Зоосемизм сова включает другие характеризующие признаки: 'чувствующий себя вечером, ночью бодрее, работоспособнее, чем утром' $[13$, c. 331].

Зооним трутень во фразеологии ассоциируется с представлениями: 'ленивый, бездельник' [5, с. 11]. 3оосемизм трутень включает другие характеризующие признаки: 'человек, живущий за счёт чужого труда' [13, с. $107 ; 18$, с. 198$]$.

Зооним сыч во фразеологии ассоциируется с представлениями:'любитель поспать' [5, с. 10]. Зоосемизм сыч включает другие характеризующие признаки: 'угрюмый и нелюдимый' [13, с. 99].

Кроме того, у зоосемизмов конь, медведь, телёнок / телок выявляются противоположные признаки.

Зооним конь во фразеологии ассоциируется с представлениями: 'дряхлый, старый, больный, уставший, здоровый, сильный, выносливый, работящий, упорный, сильно храпеть' [5, с. 11].

Зоосемизм конь включает не только совпадающие признаки, но и противоположные характеризующие признаки: 'здоровый и сильный - не утруждающий себя работой '[18, с. 82].

Образ медведь во фразеологии ассоциируется с признаками: 'грязный, лохматый, обросший, ходит переваливаясь, крепко спящий, ловкий, медлительный, неповоротливый, неуклюжий, сильный, смелый, неприкаянный, недовольный' [5, с. 9].

У зоосемизма медведь отражается часть из этих признаков, но также актуализированы противоположные признаки: 'неуклюжий - неловкий и невоспитанный' [13, с. 332]. В словаре Л.В. Дуличенко: 'крупный, сильный, грузный и неуклюжий - неловкий' [18, с. 101].

Зооним телёнок / телок во фразеологии ассоциируется с представлениями: 'глупый, угрюмый, мрачный, недовольный, сердитый, вольный, беспомощный, ласковый, неуместно бурно проявляющий чувства, льстец, подхалим, нахальный' [5, с. 10].

Зоосемизм телёнок / телок включает не только совпадающие признаки, но и противоположные характеризующие признаки: 'безответный или слишком простодушный, глуповатый - безвольный' [18, с. 193].

Между РСС [13] и СОС [18] выявляются расхождения в описании метафорических значений зоосемизмов ишак, кукушка, обезьяна, скотина.

Зооним ишак во фразеологии ассоциируется с представлениями: 'флегматичный, смирный, терпеливый, работящий' [5, с. 9]. В Семантическом словаре зоосемизм ишак включает часть этих признаков: 'безропотно выполняющий самую тяжёлую работу' [13, с. 96]. Словарь Л.В. Дуличенко указывают иные признаки:'упрямый, глупый' $[18$, с. 71].

Зооним кукушка во фразеологии ассоциируется с представлениями: 'беззаботный, беспутный, непостоянный, одинокий, замкнутый' [5, с. 9]. В Семантическом словаре зоосемизм кукушка имеет иные признаки: 'женщина, бросившая своего ребёнка, оставившая своих детей' [13, с. 187]. Словарь Л.В. Дуличенко включает часть этих признаков:'легкомысленная' [18, с. 88].

Зооним обезьяна во фразеологии ассоциируется с представлениями: 'некрасивый, ловкий, кривляющийся' [5, с. 10]. В Семантическом словаре зоосемизм обезьяна имеет иные признаки: 'склонный к бездумному подражанию другим, гримасник, кривляка' [13, с. 103]. Словарь Л.В. Дуличенко включает не только часть этих признаков, но и другие признаки: 'очень некрасивый, уродливый - гримасничает, кривляется, передразнивает других' $[18$, с. 117].

Зооним скотина во фразеологии ассоциируется с представлениями: 'грубый, похотливый, хам, грубиян' [5, c. 10]. В Семантическом словаре зоосемизм скотина отражает часть из этих признаков: 'грубый и подлый' [13, с. 119]. Словарь Л.В. Дуличенко включает не только часть этих признаков, но и другие признаки: 'грубый, - низкий'[18, с. 175].

Изученные материалы иллюстрируют регулярные расхождения между ассоциативными признаками зоонимов во фразеологизмах и характеризующими признаками зоосемизмов.

\section{4. Выво $\Delta ы$}

Подводя итоги сопоставительному исследованию зоонимов в составе фразеологических единиц и зоосемизмов, как они представлены в научной литературе и в русской лексикографии, констатируем следующее. 
1. В научной терминологии отсутствует четкое разграничение понятий зооним в составе фразеологических единиц и зоосемизм. Соответственно не разграничиваются термины зооним и зоосемизм. Исследования, в которых специально рассматриваются метафорические значения русских зоонимов - зоосемизмы - единичны.

2. Количественный состав зоонимов, отражающихся во фразеологизмах, и мотивированных зоонимами названий лиц - зоосемизмов - существенно различается.

«Идеографическом словаре русских фразеологизмов с названиями животных» Т.В. Козловой в устойчивых сочетаниях выявлено 283 зоонима. Русские зоосемизмы, представленные в «Русском семантическом словаре» и в «Словаре обидных слов» Л.В. Дуличенко содержат 162 зоосемизма. Таким образом, фразеологические значения зоонимов представлены более разнообразно, чем метафорические значения.

3. У большинства зоонимов, отмеченных в составе фразеологических единиц, отсутствует метафорическое зоосемическое значение. И аналогично большинство зоосемизмов образованы от зоонимов, не отмеченных в составе фразеологизмов. Наличие фразеологического значения, наряду с зоосемическим, нами выявлено только у 45 названий животных.

4. Метафорические значения, как правило, у́же совокупности характеризующих фразеологических значений зоонима.

5. Метафорические и фразеологические характеризующие значения зоонимов совпадают лишь отчасти. При исследовании материала мы выявили следующие три типа ситуаций.
1. У зоосемизма при метафоризации актуализирована часть характеризующих признаков, ассоциирующихся с соответствующим зоонимом в составе фразеологизмов: гусыня, зверь, змея, кобель, корова, лиса / лисица, осёл, петух, попугай, сорока, червь, ягнёнок, индюк, кот.

2. Помимо части признаков, характерных для зоонима во фразеологии, у зоосемизма актуализирован дополнительный характеризующий признак или дополнительные признаки: бык, боров, голубь, кляча, коза, ласточка, лошадь, пава, птича, сокол.

3. Зооним во фразеологии и зоосемизм различаются характеризующими признаками: волк, ворона, гусь, жеребеи, кобыла / кобылица, лев, овца, пёс, рыба, сова, трутень, сыч; эти признаки могут даже противоречить друг другу: конь, медведь, телёнок/ телок.

4. Исследование выявляет расхождения между РСС [13] и СОС [18] в описании метафорических значений зоосемизмов ишак, кукушка, обезьяна, скотина и соответственно в их отношениях с фразеологическими значениями.

5. Фразеологически связанные значения зоонимов и зоосемические значения не могут рассматриваться как вариативные. Необходимо последовательное разграничение соответствующих языковых феноменов в терминологии, в научных исследованиях, в русскоязычной и двуязычной лексикографии. Такое разграничение важно также в преподавании русского языка как иностранного.

Исследование выполнено при финансовой поддержке стипендии Правительства Шэньчжэня и Университета мГУ-ППИ в Шэньчжэне.

\section{ЛИТЕРАТУРА}

1. Гаврилюк М.А. Зооморфная метафора как фрагмент китайской и русской языковых картин мира // Вестник МГлУ. 2015, № 2. С. 109-119.

2. Добровольский Д.О. Регулярная многозначность в сфере идиоматики // Сокровенные смыслы: Слово. Текст. Культура: Сб. статей в честь Н.Д. Арутюновой / Отв. ред. Ю.Д. Апресян. М.: Языки славянской культуры, 2004. - С. 77-88.

3. Кацитадзе Э.А. Метафоризация зоонимов в немецком языке: Автор. дис. канд. филол. наук. Тбилиси, 1985. - 19 с.

4. Киприянова А.А. 06 ассоциативной семантической нагрузке зоосемизмов // Семантика языковых единиц. Доклады VI Международной конференции. M., 1998. -23 c.

5. Козлова Т.В. Идеографический словарь русских фразеологизмов с названиями животных. М.: Издательство «Дело и Сервис», 2001. - 208 с.

6. Курбанов И.А. Анализ зоосимволики в русском и английском языках: дис. канд. филол. наук. М., 2000. - 437 с.

7. Ли Имо. Зоосемизмы в русской и китайской лексикографии: род и пол // Мир науки, культуры, образования (Горно-Алтайск), 2020, № 5. С. $289-295$.

8. Маслова А.С. Использование индекса инвективноти при характеристике зоометафор в современном русском языке // Научные ведомости БелГУ. Серия гуманитарные науки. 2013, № 13. С. 51-58.

9. Москвин В.П. Русская метафора: параметры классификации // Филологические науки. 2002, № 2. С. 66-74.

10. Огдонова Ц.Ц. Зооморфная лексика как фрагмент русской языковой картины мира: Автор. дис. канд. филол. наук. Иркутск, 2000. - 21 с.

11. Падучева Е.В. Метафора и её родственники // Сокровенные смыслы: Слово. Текст. Культура: Сб. статей в честь Н.Д. Арутюновой / Отв. ред. Ю.Д. Апресян. М.: Языки славянской культуры, 2004. С.187-203.

12. Патюкова Р.В. Зооморфная метафора как одна из составляющих образности публичного выступления (на материале английского и русского языков) // 
Вестник Адыгейского государственного университета. Серия 2: Филология и искусствоведение. 2009, № 2. С. 193-199.

13. Русский семантический словарь. Толковый словарь, систематизированный по классам слов и значений / Под общей ред. Шведовой Н.Ю. М.: «АЗБУкОВНИК», 2000. T. I.

14. Скляревская Г.Н. Метафора в системе языка. Санкт-Петербург: Наука. 1993. - 150 с.

15. Соколова А.Г. Кошка и Собака в русском и немецком языках (на материале толковых и фразеологических словарей) [электронный pecypc]. URL: http:// www.russian.sfpgu.ru/ files/sokolova.pdf (дата обращения: 17.08.2020).

16. Солнцева Н.В. Сопоставительный анализ зоонимов русского французского и немецкого языков в этно-семантическом аспекте: Автор. дис. канд. филол. наук. Омск, 2004. - 31 c.

17. Солодкин Р.Я. К вопросу о терминологических особенностях обозначения наименований животных во вторичной номинации // Сборник трудов молодых учёных. 2009, № 4. С. 68-73.

18. Дуличенко Л.В. Словарь обидных слов: наименования лиц с негативным значением. Тарту: Тартуский университет, 2000.

19. Цай Сяо-лин. Зоонимы и зоосемизмы в отношении к роду и биологическому полу. Проблемы изучения и преподавания русского языка и литературы: Вестник факультета русского языка и литературы. Тайбэй, 2006, № 9. С. 84-93.

20. Шульга М.В. Грамматические оппозиции в истории морфологии имени. М.: Индрик, 2017. - 256 с.

\section{(c) Ли Имо (liyimo@mail.ru).}

Журнал «Современная наука: актуальные проблемы теории и практики»

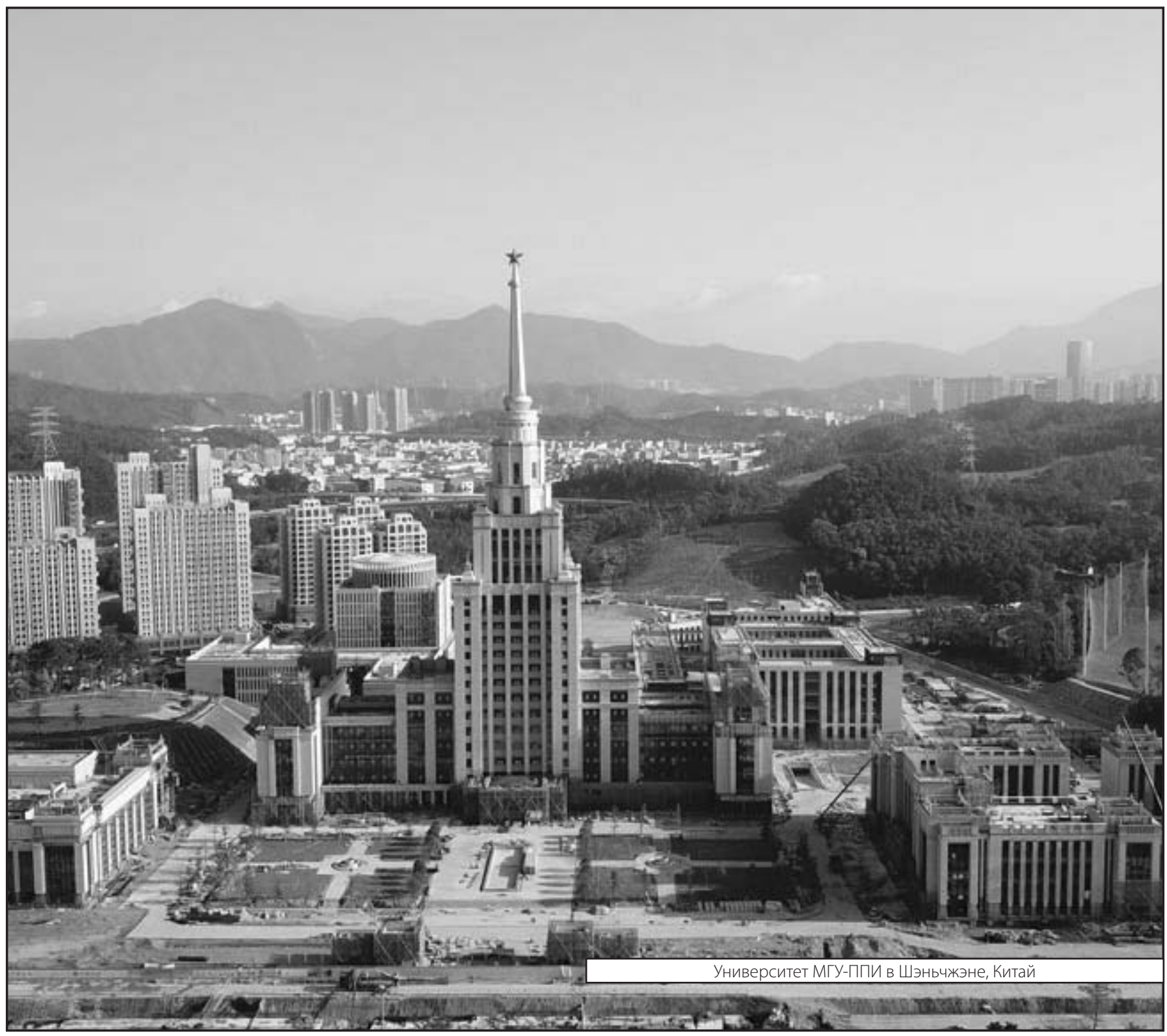

